\title{
THE NEUROPEPTIDES GALANIN AND GALANIN (1-15) IN DEPRESSION-LIKE BEHAVIOURS
}

Carmelo Millón ${ }^{1 *}$, Antonio Flores-Burgess ${ }^{1}$, Manuel Narváez ${ }^{1}$, Dasiel 0. Borroto-Escuela², Belén Gago ${ }^{1}$, Luis Santín ${ }^{3}$, Estela Castilla-Ortega ${ }^{3}$, José Ángel Narváez ${ }^{1}, K_{j e l l ~ F u x e}^{2} \&$ Zaida Díaz-Cabiale ${ }^{1}$.

1. Universidad de Málaga, Instituto de Investigación Biomédica de Málaga, Facultad de Medicina, Departamento de Fisiología, Campus de Teatinos s/n, 29071 Málaga, Spain.

2. Department of Neuroscience, Karolinska Institute, Stockholm, Sweden

3. Universidad de Málaga, Instituto de Investigación Biomédica de Málaga, Facultad de Psicología, Departamento de Psicobiología, Campus de Teatinos s/n, 29071 Málaga, Spain.

*Corresponding author:

Carmelo Millón Peñuela, PhD

Departamento de Fisiología

Facultad de Medicina

Universidad de Málaga

Campus de Teatinos s/n. 29080 Málaga, Spain

E-mail: carmelomp@uma.es 
Millón et al., 2016

Neuropeptides 


\section{Abstract}

Galanin is a 29 amino acid neuropeptide widely distributed in neurons within the central nervous system. Galanin exerts its biological activities through three different $G$ protein-receptors and participates in a number of functions, including mood regulation. Not only Galanin but also Galanin N-terminal fragments like Galanin(1-15) are active at the central level. In this work, we review the latest findings in studies on Galanin and Galanin(1-15) in depression-related behaviours. Our focus is on animal models for depression, and we pay some attention to research data obtained in human studies. Since Serotonin (5-HT), especially through 5-HT1A, and Galanin receptors interact at both pre-and postsynaptic level, the development of drugs targeting potential $\mathrm{GAL}_{1}-\mathrm{GAL}_{2}-5$ HT1A heteroreceptor complexes linked to the raphe-hippocampal 5-HT neurons may represent new treatment strategies in depression.

Key words: depression, galanin 


\section{Introduction}

Mood disorders, including depression and anxiety, are among the most prevalent mental illnesses with high socioeconomic impact (Gelenberg, 2010; Wittchen et al., 2011). Although the underlying mechanisms have not yet been clearly defined in the last decade the importance of the role of neuropeptides, including Galanin (GAL), and/or their receptors in the treatment of stress-related mood disorders is becoming increasingly apparent (Kormos et al., 2013).

GAL is a 29 amino acid neuropeptide (Tatemoto et al., 1983) widely distributed in neurons within the central nervous system (CNS) including raphe nuclei, cerebral cortex and hippocampus (Jacobowitz et al., 2004) among other nuclei involved in mood disorders. Three GAL receptor subtypes ( $G A L_{1-3}$ receptors) have been described (Branchek et al., 2000; Mitsukawa et al., 2008). GAL ${ }_{1}$ and $\mathrm{GAL}_{2}$ receptors, in particular, are found in many regions of the CNS as demonstrated with in situ hybridization, radioligand binding, and immunohistochemical studies (Jacobowitz et al., 2004) and have all high affinity for $\mathrm{GAL}$. $\mathrm{GAL}_{1}$ and $\mathrm{GAL}_{3}$ receptors mainly activate inhibitory $\mathrm{G}$ proteins $\mathrm{Gi} / \mathrm{Go}$, while $\mathrm{GAL}_{2}$ receptor primarily couples to $\mathrm{Gq} / \mathrm{G} 11$ to mediate excitatory signaling (Branchek et al., 2000).

The three GAL receptors participate in a number of functions in the CNS including neuroendocrine levels, mood regulation, pain control, cardiovascular functions, addiction and food intake (Lu et al., 2007; Kuteeva et al., 2008; Mitsukawa et al., 2008; Diaz-Cabiale et al., 2010; Juhasz et al., 2014; Lang et al., 2015)

Not only GAL but also the GAL fragments like GAL N-terminal fragment 1-15 [GAL(1-15)] are active in the CNS (Hedlund et al., 1996; Diaz-Cabiale et al., 2005; Diaz-Cabiale et al., 2010; Millon et al., 2015; Millon et al., 2016). Structure-activity studies described that in the brain, N-terminal fragments of GAL are biologically active, whereas C-terminal fragments are inactive (DiazCabiale et al., 1998) and they act as agonists in several physiological functions (Diaz-Cabiale et al., 1998; Diaz-Cabiale et al., 2005), suggesting a receptor- 
mediated action. Although the three GAL receptors subtypes show higher affinity for GAL than for GAL(1-15) (Branchek et al., 1998), the presence of specific binding sites for this GAL fragment in the CNS also in areas lacking [125I]- GAL binding sites indicated a powerful role of GAL fragments, especially in the dorsal hippocampus, neocortex and striatum (Hedlund et al., 1992). Only GAL(1-15), but not GAL, can antagonically modulate the serotonin 5-HT1A receptors in the dorsal hippocampus, and this effect was blocked by the GAL receptor antagonist M35 (Hedlund et al., 1994). In the ventral limbic cortex, Nterminal GAL fragments can more stringy and more potently reduce posjunctionals 5-HT1A receptor recognition than GAL, where high-affinity GAL receptors also exist (Diaz-Cabiale et al., 2000; Diaz-Cabiale et al., 2010). The formation of $\mathrm{GAL}_{1} / \mathrm{GAL}_{2}$ heteroreceptors highly specific for $\mathrm{GAL}$ fragments will explain the different effects between GAL and GAL(1-15) (Fuxe et al., 2008; Fuxe et al., 2012; Millon et al., 2015).

In this work, we review the latest findings in studies on GAL and GAL(1-15) in depression-related behaviours. Our focus is on animal models for depression, and we pay some attention to research data obtained in human studies.

\section{GALANIN IN DEPRESSION}

A major impediment in depression research is the lack of validated animals' models. Animals not only lack consciousness of self, self-reflection and consideration of others but also hallmarks of the disorder such as depressed mood, low self esteem or suicidal intent are hardly accessible in non-human (Deussing, 2006). However, depression, as other mental disorders, constitutes of intermediate or so-called endophenotypes that can be reproduced independently and evaluated in animals, including physiological, endocrinological and neuroanatomical alterations as well as behavioural traits. Numerous behavioural paradigms have been established to elucidate face and construct validity of depression models, including antidepressant-screening test (Deussing, 2006). 
The forced swimming test (FST), the most used paradigm to assess depression- and antidepressant- like behaviour, also known as the 'behavioural despair' test, was developed by Porsolt et al. (Porsolt et al., 1977) as a rodent model for predicting the clinical efficacy of antidepressant drugs (Bogdanova et al., 2013). The FST takes advantage of the observation that rodents, following initial escape-oriented movements, rapidly adopt a characteristic immobile posture in an inescapable cylinder filled with water. In this paradigm, immobility is interpreted as a passive stress-coping strategy or depression-like behaviour (behavioural despair) (Deussing, 2006).

Fuxe's Laboratory, around nineties, reported the first evidence of the involvement of GAL in depression. In animal models, GAL administered into the lateral ventricle (i.c.v) reduced serotonin (5-HT) metabolism in ventral limbic cortex, hippocampal formation, and fronto-parietal cortex probably via direct inhibitory actions on dorsal raphe (DR) 5- $\mathrm{HT}$ nerve cells reducing their firing rates (Fuxe et al., 1988b). These results suggested based on the 5-HT hypothesis of depression that GAL, may contribute to depression by reducing firing in the ascending 5-HT neurons (Fuxe et al., 1988b).

GAL in the rat ventral tegmental area (VTA) induced in a dose-dependent manner an increased in immobility time in the FST (Weiss et al., 1998), an effect that was blocked by the coinfusion of the GAL receptor antagonist M35. I.c.v. GAL also resulted in an increase of immobility time in FST confirming that GAL may induce depression-like phenotype (Kuteeva et al., 2007). In the rat, intraperitoneal injection of galnon or galmic, GAL receptor agonists, reduced immobility time in the rat FST, indicating an antidepressant-like effect of systemically GAL receptor agonists (Bartfai et al., 2004; Lu et al., 2005) (Table 1).

The role of GAL in depression-like behaviour has been analysed in genetically modified mice. Mice over-expressing GAL under the platelet-derived growth factor-B promoter (GalOE-P) displayed an increased immobility in the FST, suggesting a depression-like behaviour (Kuteeva et al., 2005; Kuteeva et al., 2008). However, Holmes et al. (2005) (Holmes et al., 2005) failed to show such 
alterations in GAL over-expressing mice under the dopamine- $\beta$-hydroxylase promoter (GalOE-D) and $\mathrm{GAL}_{1}$ receptor knockout (KO) mice (Table 1). Importantly, GalOE-P but not GalOE-D mice showed an augmentation of hippocampal noradrenaline (NA) and 5-HT release probably indicating that the mechanisms underlying the increase of immobility in GalOE-P can be related to modulation of NA and 5-HT transmission.

In a genetic rat model of depression, the Flinder sensitive line, which displays a high immobility in FST, an up-regulation of the GAL receptor binding sites, is found in the DR, and reduces GAL fiber density in the hippocampus and hypothalamus. The results indicate that enhancement of GAL receptors function in the DR rich in 5-HT neurons could be a mechanism involved in the production of depressive-like activity in this animal model of depression (Bellido et al., 2002).

\section{Galanin Receptors in depression}

Several studies suggest that $\mathrm{GAL}_{1} / \mathrm{GAL}_{3}$ receptors can contribute to the prodepressive effect of GAL. I.c.v infusion of $\mathrm{GAL}_{1}$ receptor agonist (M617) elevated the immobility time in the FST, similar to GAL itself. Moreover, the depression-like behavior in rats exposed to chronic mild stress was related to an elevated expression of $\mathrm{GAL}_{1}$ receptor in the ventral periaqueductal gray (Wang et al., 2016). Furthermore, administration of $\mathrm{GAL}_{3}$ receptor antagonists to rat and mice produced antidepressant-like effects in both FST and the tail suspension test (TST) (Swanson et al., 2005; Barr et al., 2006) (Table 1). The TST is another prominent test, which relies on similar assumptions and interpretations as the FST (Steru et al., 1985). In the TST, animals are suspended by their tails for a defined period of time, and their immobility is assessed (Deussing, 2006).

Stimulation of the $\mathrm{GAL}_{2}$ receptor, in contrast, produces antidepressant-like effects. The i.c.v. $\mathrm{GAL}_{2}$ receptor agonist AR-M1896 decreased the immobility time in the FST, while the $\mathrm{GAL}_{2}$ receptor antagonist (M871) elevated the 
immobility time in the FST (Kuteeva et al., 2008). Recent studies shown that systemically active $\mathrm{GAL}_{2}$ receptor agonist reduced the immobility time in the FST and in the TST, confirming the potential antidepressant effect of $\mathrm{GAL}_{2}$ receptor (Saar et al., 2013b; Saar et al., 2013a) (Table 1).

$\mathrm{GAL}_{1}$ receptor (Holmes et al., 2003), $\mathrm{GAL}_{3}$ receptor (Brunner et al., 2014) and $\mathrm{GAL}_{2}$ receptor (Bailey et al., 2007) null mutant displayed an anxiogenic-like phenotype in the elevated plus maze; nevertheless, neither $\mathrm{GAL}_{1}$ receptor knockout (Holmes et al., 2005) nor $\mathrm{GAL}_{2}$ receptor knock out (Gottsch et al., 2005) mice differed from their wild-type littermate in the TST. On the contrary, transgenic mouse over-expressing $\mathrm{GAL}_{2}$ receptor-enhanced, green fluorescent protein constructed under the platelet-derived growth factor-B promotor decreased levels of immobility in the FST (Le Maitre et al., 2011). GAL 3 receptor knock out mice displayed a trend toward decreased immobility time in the TST, indicating a reduction in depression-like behaviour (Brunner et al., 2014) (Table 1).

All these results indicate that stimulation of $\mathrm{GAL}_{2}$ receptor may be responsible for antidepressant-like effects, whereas $G A L_{1}$ and $G A L_{3}$ receptors seem to contribute to the prodepressive effects of GAL.

In addition, both chronic treatments with the selective serotonin reuptake inhibitor (SSRI) fluoxetine and electroconvulsive treatment increase GAL mRNA levels in the $\mathrm{DR}$ of the rat, accompanied by an increase in $\mathrm{GAL}_{2}$ receptor, but not $\mathrm{GAL}_{1}$ receptor, binding sites in this monoaminergic nuclei. Moreover, coadministration of GAL receptors antagonist M40 blocked the behavioural effect of fluoxetine in the FST, suggesting that the antidepressant action of fluoxetine can, at least partially, be related to an increase in GAL-mediated transmission (Lu et al., 2005; Kuteeva et al., 2008). Yamada and co-workers found that after four-week treatment with sertraline, a SSRI, GAL but not $\mathrm{GAL}_{2}$ receptor was upregulated in the ventral dentate gyrus (Yamada et al., 2013). Moreover, the chronic administration of desipramine, a tricyclic antidepressant, paroxetine, a SSRI, and phenelzine, a monoamine oxidase inhibitor, affected mRNA for GAL and GAL receptors (Rovin et al., 2012). In the VTA, the most marked change in 
mRNA produced by these drugs was a decrease in mRNA for $G A L_{2}$ receptor (Rovin et al., 2012). However, Venlafaxine, a selective serotonin and noradrenalin reuptake inhibitor, does not alter transcript levels of GAL or its three receptors (Petschner et al., 2016). These results suggest that the effects on $\mathrm{GAL}$ and GAL receptors are not uniform among antidepressants and may be related to certain pharmacological properties (Petschner et al., 2016).

Some human data support the involvement of GAL and its receptors in mood disorders. Thus, GAL given intravenously induced antidepressant-like effects, indicated by a suppression of REM sleep in healthy male volunteers (Murck et al., 2004). Recently in a genome wide screening, the single nucleotide polymorphism of GAL gene has been associated with major depression (Wray et al., 2012). Moreover, a work reported that variants in genes for GAL, and its receptors confer an increased risk of depression and anxiety in people who experienced childhood adversity or recent negative life events (Juhasz et al., 2014). Furthermore, significant positive correlation between plasma GAL level and depression severity has been demonstrated suggesting that plasma GAL levels may be an important biomarker for depression (Wang et al., 2014). Recent findings showed that $G A L, G A L_{1}$ and $G_{2} L_{3}$ receptors mRNA levels were increased in DR nucleus and GAL and $\mathrm{GAL}_{3}$ receptor in Locus Coeruleus (LC) in brains from depressed persons who had committed suicide (Barde et al., 2016).

All these studies suggest the importance of GAL and its receptors in the pathogenesis of depression.

\section{GALANIN(1-15) IN DEPRESSION}

We have analysed the role of GAL(1-15) on the depression-like behaviour using two tests, the FST and the TST. 
In the FST, i.c.v. GAL(1-15) 3 nmol significantly increased the immobility time and decreased the time of climbing by $44 \%$ and $46 \%$ respectively. In addition, this effect was shown with the administration of GAL(1-15) 6 nmol (Millon et al., 2015). The same pattern of response was observed in the TST, GAL(1-15) at the dose of $3 \mathrm{nmol}$ also significantly increased the immobility behaviour recorded during the 6 min of testing (Millon et al., 2015) (Table 1).

These results in both behavioural tests suggest that GAL(1-15) could evoke a strong depression-like behaviour.

When we compared the effects in FST induced by GAL and GAL(1-15), we observed that the increase in the immobility induced by $G A L(1-15)$ was significantly higher than the one induced by GAL (Millon et al., 2015). Moreover, in climbing behaviour, GAL(1-15) also induced a stronger decrease in climbing response compared with GAL (Millon et al., 2015).

In the open field test and in the light-dark box (Prut et al., 2003), we observed that only GAL(1-15) and not GAL modifies the anxiety parameters (Millon et al., 2015) (Table 1). GAL produced anxiolytic-like effects only in animals tested under heightened stress conditions (Barrera et al., 2005; Millon et al., 2015), on contrary, GAL(1-15) induced an anxiogenic-like effect without a stress situation (Millon et al., 2015).

All these results confirm an important role of GAL(1-15) in mood disorders.

Galanin Receptors involved in GAL(1-15)-mediated effect: siRNA $G A L_{1}$ receptor or $G A L_{2}$ receptor Knockdown rats.

Gene silencing by RNA interference is as a new method of inhibiting the expression of targeted genes and inducing knockdown of associated proteins both in vitro and in vivo (Nakajima et al., 2012). This RNA interference has been applied in experimental investigations in the treatment of illnesses, including neuropsychiatric disorders (Nakajima et al., 2012). Dharmacom Accell siRNA is 
one type of naked siRNA modified chemically resulting in robust silencing of selected genes and knockdown of associated proteins (Nakajima et al., 2012).

We used the Accell siRNA system for generating $G A L_{1}$ or $G A L_{2}$ receptors knockdown (KD) rats to analyze the involvement of GAL receptors in $G A L(1-$ 15)-mediated effects.

Rats were i.c.v. injected with $5 \mu \mathrm{g}$ of Accell Smart pool siRNA GAL ${ }_{1}$ receptor or siRNA GAL 2 receptor (Dharmacom), or $5 \mu \mathrm{l}$ of vehicle (Accell siRNA Delivery Media). We have analysed the reduction produced by siRNAs with a timecourse curve performed in siRNA $G_{2}$ or $\mathrm{GAL}_{1}$ receptors animals and we examined the mRNA for $\mathrm{GAL}_{2}$ and $\mathrm{GAL}_{1}$ receptors in the dorsal hippocampus by real-time quantitative polymesare chain reaction (RT-PCR) in these animals.

In figure $1 \mathrm{~A}$, it is shown that a single injection of siRNA $\mathrm{GAL}_{2}$ receptor induced a strong reduction of $m R N A G_{2}$ receptor $(p<0.05)$ at day 4 and 6 after siRNA treatment (Millon et al., 2015). However, the icv injection of siRNA GAL 2 receptor lacked effect in mRNA $G_{1}$ receptor expression (Fig. 1B) [unpublished results].

The single injection of SiRNA $\mathrm{GAL}_{2}$ receptor produced the strongest decreased in the receptor expression 8 days after the injection by $35 \%$ in CA1 of the dorsal hippocampus and by $50 \%$ in piriform cortex (Millon et al., 2015).

The same pattern of response in mRNA expression was shown after the administration of siRNA $G A L_{1}$ receptor. A strong reduction of $m R N A G A L_{1}$ receptor at 8 days $(p<0.001)$ was produced by siRNA GAL 1 receptor (Fig. $1 C)$ (Millon et al., 2015). Again, the Accell siRNA system is specific, since that injection of siRNA $G_{1} L_{1}$ receptor did not modify the mRNA GAL 2 receptor expression (Fig. 1D) [unpublished results].

The Down-regulation of $\mathrm{GAL}_{2}$ or $\mathrm{GAL}_{1}$ receptors did not affect any parameters in the FST or in the open field test (OFT) (Table 1). However, this decrease in $\mathrm{GAL}_{2}$ or $\mathrm{GAL}_{1}$ receptors was enough to block the depression- and anxiogeniclike effect of $\operatorname{GAL}(1-15)$ in both tests (Millon et al., 2015). Thus, GAL(1-15) at 
the dose of $3 \mathrm{nmol}$ lacked effect on immobility, climbing and swimming time in the $F S T$ in siRNA $G A L_{2}$ receptor or in $G_{1} L_{1}$ receptor $K D$ rats. In the OFT the same pattern of response was observed, since GAL(1-15) did not affect neither number of entries as the time spent in the central square of open field in $\mathrm{GAL}_{2}$ receptor or in $\mathrm{GAL}_{1}$ receptor $\mathrm{KD}$ rats (Millon et al., 2015).

The fact that $\mathrm{GAL}_{1}$ and $\mathrm{GAL}_{2}$ receptors are needed to obtain $\mathrm{GAL}$ (1-15)-effect confirms the hypothesis that GAL(1-15) preferring sites may be formed through the formation of $\mathrm{GAL}_{1} / \mathrm{GAL}_{2}$ heteroreceptor complexes which lead to conformational changes in their GAL recognition sites converting $\mathrm{GAL}_{1}$ and/or $G_{2} L_{2}$ receptors into $G A L$ recognition fragment preferring binding sites with reduced affinity for GAL (Fuxe et al., 2008; Fuxe et al., 2012). In recent work, Borroto-Escuela et al. analyzed the existence of $\mathrm{GAL}_{1} / \mathrm{GAL}_{2}$ heteroreceptor complex in co-transfected HEK cells through Bioluminescence Resonance Energy Transfer $\left(B R E T^{2}\right.$ ) giving evidence for the existence of $G_{A L} / G A L_{2}$ heteroreceptor complexes (Borroto-Escuela et al., 2014). A differential role of GAL and GAL(1-15) in signaling cascades Gi/o-Adenylate cyclase (AC)-Protein kinase A (PKA) and Gq-Phospholipase C (PLC)-Protein kinase C (PKC)/Ca ${ }^{2+}$ was observed with cyclic adenosine monophosphate response element (CRE) and nuclear factor of activated T-cells (NFAT) -luciferase reporter gene assays in co-expressing $\mathrm{GAL}_{1}$ and/or $\mathrm{GAL}_{2}$ receptors HEK293T cells (Borroto-Escuela et al., 2014).

The formation of $\mathrm{GAL}_{1} / \mathrm{GAL}_{2}$ heteroreceptor complexes with high affinity for $\operatorname{GAL}(1-15)$ can help explain the fact that $\operatorname{GAL}(1-15)$ induces a stronger action than GAL at the behavioral level. As described is this review $G A L_{2}$ receptor may induce antidepressant actions via $G q / G 11$ mediated $G A L_{2}$ receptor signaling. It seems possible that in the $\mathrm{GAL}_{1} / \mathrm{GAL}_{2}$ heteroreceptor complex the $\mathrm{GAL}_{2}$ receptor protomer signals in a different way upon activation by its preferred ligand $G A L(1-15)$ leading to its strong depression-like action. Alternatively, the $G A L(1-15)$ activation of the $G_{1} L_{1}$ receptor protomer may via an allosteric receptor-receptor interaction inhibit the $\mathrm{Gq} / \mathrm{G} 11$ mediated signaling of the $\mathrm{GAL}_{2}$ receptor protomer and switch it towards Gi/o mediated signaling. In 
this way both $\mathrm{GAL}_{1}$ and $\mathrm{GAL}_{2}$ receptors protomers become coupled to $\mathrm{Gi} / \mathrm{o}$ which may lead to the strong depression-like actions observed with $G A L(1-15)$ (Millon et al., 2015). The formation of homodimers and heterodimers among neuropeptide receptors is known (AbdAlla et al., 2005). $\mathrm{GAL}_{1}$ receptor can form homodimers (Wirz et al., 2005) and heterodimers with 5-HT1A receptors (Borroto-Escuela et al., 2010; Fuxe et al., 2012) and likely with other G-protein coupled receptors.

The existence of $\mathrm{GAL}_{1} / \mathrm{GAL}_{2}$ heteroreceptors complexes in brain tissue was demonstrated with in situ Proximity Ligation Assay (PLA) to analyze the proximity of $G A L_{1}$ and $G A L_{2}$ receptors in the dorsal hippocampus and $D R$ nuclei of the KD rats of $\mathrm{GAL}_{2}$ receptor (Millon et al., 2015). In the siRNA $\mathrm{GAL}_{2}$ receptor treated animals, PLA- positive red clusters were still observed in the dorsal hippocampus and DR (Millon et al., 2015). However, the number of $\mathrm{GAL}_{1} / \mathrm{GAL}_{2}$ complex was reduced by $40 \%$ in CA1, CA2 and dentate gyrus in dorsal hippocampus and by $60 \%$ in the DR nucleus compared with the vehicle group (Millon et al., 2015). In agreement with these results, in the siRNA GAL2 receptor treated animals the colocalization of $\mathrm{GAL}_{1}$ and $\mathrm{GAL}_{2}$ receptors was reduced in the both areas (Millon et al., 2015).

These results strongly indicate that the PLA signals obtained are specific and represent the $\mathrm{GAL}_{1}$ and $\mathrm{GAL}_{2}$ heteroreceptor complex. This reduction of the PLA signal was sufficient to block the depression- and anxiogenic-like effects of $\mathrm{GAL}(1-15)$, linking them to its actions at the $\mathrm{GAL}_{1} / \mathrm{GAL}_{2}$ heteroreceptor complex (Millon et al., 2015).

\section{Effects of Galanin on monoamine systems}

The physiological/ pathophysiological mechanisms underlying the action(s) of GAL most probably involves modulation of monoaminergic systems, in particular, the LC and DR nuclei. This was further supported by the fact that all three receptors are found in the DR and LC of rats (O'Donnell et al., 1999; Burazin et al., 2000; Mennicken et al., 2002) and that GAL is co-expressed in 
almost $40 \%$ of the serotonergic neurons in the DR (Xu et al., 1997) and in around $80 \%$ of the noradrenergic neurons in the LC (Holets et al., 1988).

I.c.v. GAL produced a reduction in basal NA release in the ventral hippocampus of the awake rat measured by microdialysis, and, significantly attenuated the increase of extracellular hippocampal NA levels evoked by desipramine (Yoshitake et al., 2003). These effects could involve the LC since GAL inhibits LC firing and produces an outward current in rat brain slices through $G_{A L} L_{1-3}$ receptors. The application of $\mathrm{GAL}_{1-3}$ receptor agonist $\mathrm{M} 961$, but not $\mathrm{GAL}_{2}$ receptor agonist AR-M1896, caused hyperpolarisation of these LC neurons (Seutin et al., 1989; Sevcik et al., 1993; Pieribone et al., 1995; Ma et al., 2001).

Moreover, Grenhoff et al. (Grenhoff et al., 1993) observed that "burst" firing of LC neurons (i.e., rapid firing of LC) released GAL from terminals on axons of LC neurons projecting to the VTA, and that the hyperpolarizing influence of GAL on dopamine (DA) cell bodies in the VTA decreased the activity of these DA neurons. This finding suggested that the hyperactivity of LC neurons observed in depression might bring about such depression-related responses by decreasing the neural activity of dopaminergic cell bodies in the VTA as the result of GAL released from LC-derived terminals in the VTA (Weiss et al., 1998).

In relation with the DR and the 5-HT system, i.c.v. GAL reduced 5-HT metabolism in ventral limbic cortex, hippocampal formation, and fronto-parietal cortex probably via direct inhibitory action on DR nerve cells reducing their firing rates (Fuxe et al., 1988b). This result is in agreement with other works where i.c.v. GAL into vecinity of the DR caused a dose-related and long-lasting inhibition of 5-HT release in the ventral hippocampus measured by microdialysis (Kehr et al., 2002). Moreover, immunohistochemistry experiments showed a strong GAL immunoreactivity staining was observed in the DR after GAL administration, suggesting that the DR was the site of action of GAL on 
hippocampal 5-HT release (Kehr et al., 2002). In agreement, i.c.v. GAL attenuates the increase in extracellular levels of 5-HT induced by SSRI citalopram, indicating that this inhibitory action persisted under conditions of serotonergic activation following reuptake inhibition by an SSRI (Yoshitake et al., 2003; Kuteeva et al., 2008). Electrophysiological experiments, where GAL inhibits the firing rate of 5-HT neurons, probably via $\mathrm{G}$ protein-coupled inwardlyrectifying potassium channel (GIRK) (Xu et al., 1998), could support these findings.

The 5-HT1A receptor seems to be a key receptor in the GALR-5-HT interaction. In the DR, i.c.v. GAL induced a time-dependent reduction in affinity and an increase in the 5-HT1A autoreceptor density (Razani et al., 2000). At postsynaptic level GAL reduced the affinity of the 5-HT1A receptors in the ventral limbic cortex (Fuxe et al., 1988a; Hedlund et al., 1996). Moreover, in hypothermia, locomotor activity and passive avoidance, i.c.v. GAL blocked postsynaptic 5-HT1A receptor function (Misane et al., 1998; Razani et al., 2001; Kehr et al., 2002). This interaction can in part be due to the existence of $G_{A L}$ 5-HT1AR heteroreceptor complexes in discrete brain regions (Borroto-Escuela et al., 2010)

The GAL(1-15) also modified 5-HT system (Millon et al., 2015). Using a rat medullary raphe-derived cell line RN33B, we observed that GAL(1-15) significantly decreased the $5-\mathrm{HT}$ immunoreactivity in the RN33B cells $(p<0.001)$ (Fig.2). Interestingly this reduction was stronger than the one induced by GAL $(p<0.001)$ (Fig.2) (Millon et al., 2015). This effect of GAL(1-15) on 5-HT immunoreactivity may indicate a possible mechanism contributing to the depression-like actions of GAL(1-15).

In this cell model, we have detected PLA- positive clusters, indicating close proximity of $G_{1} L_{1}$ and $G A L_{2}$ receptors and the possible formation of $\mathrm{GAL}_{1} / \mathrm{GLAR}_{2}$ heteroreceptor complexes (Millon et al., 2015). Therefore, the formation of $\mathrm{GAL}_{1} / \mathrm{GAL}_{2}$ heteroreceptor complexes with high affinities for GAL(1-15) can help explain the fact that GAL(1-15) induces a stronger action than GAL in the reduction of $5-\mathrm{HT}$ in the RN33B. Thus, the strong decrease on 
5-HT immunoreactivity induced by $\mathrm{GAL}(1-15)$ may indicate a mechanism contributing to the depression- like actions of GAL(1-15) (Fig. 2D) (Millon et al., 2015). Recently, we have described that GAL(1-15) enhances the antidepressant effects induced by 8-hydroxy-2-(di-n-propylamino) tetralin (8$\mathrm{OH}-\mathrm{DPAT}$ ) acting on $5-\mathrm{HT} 1 \mathrm{~A}$ receptors operating as postjunctional or as autoreceptors, confirming the importance of the interaction GALR-5-HT1A receptors (Millon et al., 2016).

\section{Conclusion}

All these data emphasized the role of GAL and its N-Terminal fragment (1-15) in depression. Moreover, GAL(1-15) induces a stronger depressive effect than GAL through $\mathrm{GAL}_{1}-\mathrm{GAL}_{2}$ heteroreceptor complexes in the raphe-limbic system. Since 5-HT, especially through 5-HT1A, and GAL receptors interact at both preand postsynaptic level, the development of drugs targeting potential $\mathrm{GAL}_{1}$ $\mathrm{GAL}_{2}-5-\mathrm{HT} 1 \mathrm{~A}$ heteroreceptor complexes linked to the raphe-hippocampal 5-HT neurons may represent new treatment in depression.

\section{Acknowledgements}

This study was supported by grants awarded by Spanish Ministry of Economy (SAF2016-79008-P), and Contratos-puente, Vicerrectorado de Investigación y Transferencia, Universidad de Málaga.

\section{References}

AbdAlla S, Abdel-Baset A, Lother H, el Massiery A, Quitterer U (2005). Mesangial AT1/B2 receptor heterodimers contribute to angiotensin II hyperresponsiveness in experimental hypertension. J Mol Neurosci 26: 185-192.

Bailey KR, Pavlova MN, Rohde AD, Hohmann JG, Crawley JN (2007). Galanin receptor subtype 2 (GalR2) null mutant mice display an anxiogenic-like 
phenotype specific to the elevated plus-maze. Pharmacol Biochem Behav 86: 8-20.

Barde S, Ruegg J, Prud'homme J, Ekstrom TJ, Palkovits M, Turecki G, et al. (2016). Alterations in the neuropeptide galanin system in major depressive disorder involve levels of transcripts, methylation, and peptide. Proc Natl Acad Sci U S A 113: E8472-E8481.

Barr AM, Kinney JW, Hill MN, Lu X, Biros S, Rebek J, Jr., et al. (2006). A novel, systemically active, selective galanin receptor type-3 ligand exhibits antidepressant-like activity in preclinical tests. Neurosci Lett 405: 111-115.

Barrera G, Echevarria DJ, Poulin JF, Laforest S, Drolet G, Morilak DA (2005). One for all or one for one: does co-transmission unify the concept of a brain galanin "system" or clarify any consistent role in anxiety? Neuropeptides 39: 289-292.

Bartfai T, Lu X, Badie-Mahdavi H, Barr AM, Mazarati A, Hua XY, et al. (2004). Galmic, a nonpeptide galanin receptor agonist, affects behaviors in seizure, pain, and forced-swim tests. Proc Natl Acad Sci U S A 101: 10470-10475.

Bellido I, Diaz-Cabiale Z, Jimenez-Vasquez PA, Andbjer B, Mathe AA, Fuxe K (2002). Increased density of galanin binding sites in the dorsal raphe in a genetic rat model of depression. Neurosci Lett 317: 101-105.

Bogdanova OV, Kanekar S, D'Anci KE, Renshaw PF (2013). Factors influencing behavior in the forced swim test. Physiol Behav 118: 227-239.

Borroto-Escuela DO, Narvaez M, Marcellino D, Parrado C, Narvaez JA, Tarakanov AO, et al. (2010). Galanin receptor-1 modulates 5-hydroxtryptamine1 A signaling via heterodimerization. Biochem Biophys Res Commun 393: 767772.

Borroto-Escuela DO, Narvaez M, Di Palma M, Calvo F, Rodriguez D, Millon C, et al. (2014). Preferential activation by galanin 1-15 fragment of the GalR1 protomer of a GalR1-GalR2 heteroreceptor complex. Biochem Biophys Res Commun.

Branchek T, Smith KE, Walker MW (1998). Molecular biology and pharmacology of galanin receptors. Ann N Y Acad Sci 863: 94-107. 
Branchek TA, Smith KE, Gerald C, Walker MW (2000). Galanin receptor subtypes. Trends Pharmacol Sci 21: 109-117.

Brunner SM, Farzi A, Locker F, Holub BS, Drexel M, Reichmann F, et al. (2014). GAL3 receptor KO mice exhibit an anxiety-like phenotype. Proc Natl Acad Sci U $S$ A 111: 7138-7143.

Burazin TC, Larm JA, Ryan MC, Gundlach AL (2000). Galanin-R1 and -R2 receptor mRNA expression during the development of rat brain suggests differential subtype involvement in synaptic transmission and plasticity. Eur $J$ Neurosci 12: 2901-2917.

Deussing JM (2006). Animal models of depression. Drug Discovery Today: Disease Models 3: 9.

Diaz-Cabiale Z, Narvaez JA, Finnman UB, Bellido I, Ogren SO, Fuxe K (2000). Galanin-(1-16) modulates 5-HT1A receptors in the ventral limbic cortex of the rat. Neuroreport 11: 515-519.

Diaz-Cabiale Z, Narvaez JA, Marcos P, Cordon MP, Covenas R, Fuxe K, et al. (1998). Galanin and NH2-terminal galanin fragments in central cardiovascular regulation. Ann N Y Acad Sci 863: 421-424.

Diaz-Cabiale Z, Parrado C, Vela C, Razani H, Covenas R, Fuxe K, et al. (2005). Role of galanin and galanin(1-15) on central cardiovascular control.

Neuropeptides 39: 185-190.

Diaz-Cabiale Z, Parrado C, Narvaez M, Millon C, Puigcerver A, Fuxe K, et al. (2010). Neurochemical modulation of central cardiovascular control: the integrative role of galanin. EXS 102: 113-131.

Fuxe K, von Euler G, Agnati LF, Ogren SO (1988a). Galanin selectively modulates 5-hydroxytryptamine $1 \mathrm{~A}$ receptors in the rat ventral limbic cortex. Neurosci Lett 85: 163-167.

Fuxe K, Ogren SO, Jansson A, Cintra A, Harfstrand A, Agnati LF (1988b). Intraventricular injections of galanin reduces $5-\mathrm{HT}$ metabolism in the ventral limbic cortex, the hippocampal formation and the fronto-parietal cortex of the male rat. Acta physiologica Scandinavica 133: 579-581. 
Fuxe K, Borroto-Escuela DO, Romero-Fernandez W, Tarakanov AO, Calvo F, Garriga $P$, et al. (2012). On the existence and function of galanin receptor heteromers in the central nervous system. Front Endocrinol (Lausanne) 3: 127.

Fuxe K, Marcellino D, Rivera A, Diaz-Cabiale Z, Filip M, Gago B, et al. (2008). Receptor-receptor interactions within receptor mosaics. Impact on neuropsychopharmacology. Brain Res Rev 58: 415-452.

Gelenberg AJ (2010). The prevalence and impact of depression. J Clin Psychiatry 71: e06.

Gottsch ML, Zeng H, Hohmann JG, Weinshenker D, Clifton DK, Steiner RA (2005). Phenotypic analysis of mice deficient in the type 2 galanin receptor (GALR2). Mol Cell Biol 25: 4804-4811.

Grenhoff J, Nisell M, Ferre S, Aston-Jones G, Svensson TH (1993).

Noradrenergic modulation of midbrain dopamine cell firing elicited by stimulation of the locus coeruleus in the rat. Journal of neural transmission. General section 93: 11-25.

Hedlund PB, Fuxe K (1996). Galanin and 5-HT1A receptor interactions as an integrative mechanism in 5-HT neurotransmission in the brain. Ann N Y Acad Sci 780: 193-212.

Hedlund PB, Yanaihara N, Fuxe K (1992). Evidence for specific N-terminal galanin fragment binding sites in the rat brain. Eur J Pharmacol 224: 203-205.

Hedlund PB, Finnman UB, Yanaihara N, Fuxe K (1994). Galanin-(1-15), but not galanin-(1-29), modulates 5-HT1A receptors in the dorsal hippocampus of the rat brain: possible existence of galanin receptor subtypes. Brain Res 634: 163167.

Holets VR, Hokfelt T, Rokaeus A, Terenius L, Goldstein M (1988). Locus coeruleus neurons in the rat containing neuropeptide $\mathrm{Y}$, tyrosine hydroxylase or galanin and their efferent projections to the spinal cord, cerebral cortex and hypothalamus. Neuroscience 24: 893-906.

Holmes A, Li Q, Koenig EA, Gold E, Stephenson D, Yang RJ, et al. (2005). Phenotypic assessment of galanin overexpressing and galanin receptor R1 knockout mice in the tail suspension test for depression-related behavior. Psychopharmacology (Berl) 178: 276-285. 
Holmes A, Kinney JW, Wrenn CC, Li Q, Yang RJ, Ma L, et al. (2003). Galanin GAL-R1 receptor null mutant mice display increased anxiety-like behavior specific to the elevated plus-maze. Neuropsychopharmacology 28: 1031-1044.

Jacobowitz DM, Kresse A, Skofitsch G (2004). Galanin in the brain: chemoarchitectonics and brain cartography--a historical review. Peptides 25: 433-464.

Juhasz G, Hullam G, Eszlari N, Gonda X, Antal P, Anderson IM, et al. (2014). Brain galanin system genes interact with life stresses in depression-related phenotypes. Proc Natl Acad Sci U S A 111: E1666-1673.

Kehr J, Yoshitake T, Wang FH, Razani H, Gimenez-Llort L, Jansson A, et al. (2002). Galanin is a potent in vivo modulator of mesencephalic serotonergic neurotransmission. Neuropsychopharmacology 27: 341-356.

Kormos V, Gaszner B (2013). Role of neuropeptides in anxiety, stress, and depression: from animals to humans. Neuropeptides 47: 401-419.

Kuteeva E, Hokfelt T, Ogren SO (2005). Behavioural characterisation of young adult transgenic mice overexpressing galanin under the PDGF-B promoter. Regul Pept 125: 67-78.

Kuteeva E, Wardi T, Hokfelt T, Ogren SO (2007). Galanin enhances and a galanin antagonist attenuates depression-like behaviour in the rat. Eur Neuropsychopharmacol 17: 64-69.

Kuteeva E, Hokfelt T, Wardi T, Ogren SO (2008). Galanin, galanin receptor subtypes and depression-like behaviour. Cell Mol Life Sci 65: 1854-1863.

Lang R, Gundlach AL, Holmes FE, Hobson SA, Wynick D, Hokfelt T, et al. (2015). Physiology, signaling, and pharmacology of galanin peptides and receptors: three decades of emerging diversity. Pharmacological reviews 67: 118-175.

Le Maitre TW, Xia S, Le Maitre E, Dun XP, Lu J, Theodorsson E, et al. (2011). Galanin receptor 2 overexpressing mice display an antidepressive-like phenotype: possible involvement of the subiculum. Neuroscience 190: 270-288. 
Lu X, Sharkey L, Bartfai T (2007). The brain galanin receptors: targets for novel antidepressant drugs. CNS \& neurological disorders drug targets 6: 183-192.

Lu X, Barr AM, Kinney JW, Sanna P, Conti B, Behrens MM, et al. (2005). A role for galanin in antidepressant actions with a focus on the dorsal raphe nucleus. Proc Natl Acad Sci U S A 102: 874-879.

Ma X, Tong YG, Schmidt R, Brown W, Payza K, Hodzic L, et al. (2001). Effects of galanin receptor agonists on locus coeruleus neurons. Brain Res 919: 169174.

Mennicken F, Hoffert C, Pelletier M, Ahmad S, O'Donnell D (2002). Restricted distribution of galanin receptor 3 (GalR3) mRNA in the adult rat central nervous system. J Chem Neuroanat 24: 257-268.

Millon C, Flores-Burgess A, Narvaez M, Borroto-Escuela DO, Santin L, Parrado $\mathrm{C}$, et al. (2015). A role for galanin N-terminal fragment (1-15) in anxiety- and depression-related behaviors in rats. Int J Neuropsychopharmacol 18: 1-13.

Millon C, Flores-Burgess A, Narvaez M, Borroto-Escuela DO, Santin L, Gago B, et al. (2016). Galanin (1-15) enhances the antidepressant effects of the 5-HT1A receptor agonist 8-OH-DPAT: involvement of the raphe-hippocampal 5-HT neuron system. Brain Struct Funct 221: 4491-4504.

Misane I, Razani H, Wang FH, Jansson A, Fuxe K, Ogren SO (1998). Intraventricular galanin modulates a 5-HT1A receptor-mediated behavioural response in the rat. Eur $J$ Neurosci 10: 1230-1240.

Mitsukawa K, Lu X, Bartfai T (2008). Galanin, galanin receptors and drug targets. Cell Mol Life Sci 65: 1796-1805.

Murck H, Held K, Ziegenbein M, Kunzel H, Holsboer F, Steiger A (2004). Intravenous administration of the neuropeptide galanin has fast antidepressant efficacy and affects the sleep EEG. Psychoneuroendocrinology 29: 1205-1211.

Nakajima H, Kubo T, Semi Y, Itakura M, Kuwamura M, Izawa T, et al. (2012). A rapid, targeted, neuron-selective, in vivo knockdown following a single intracerebroventricular injection of a novel chemically modified siRNA in the adult rat brain. J Biotechnol 157: 326-333. 
O'Donnell D, Ahmad S, Wahlestedt C, Walker P (1999). Expression of the novel galanin receptor subtype GALR2 in the adult rat CNS: distinct distribution from GALR1. J Comp Neurol 409: 469-481.

Petschner P, Juhasz G, Tamasi V, Adori C, Tothfalusi L, Hokfelt T, et al. (2016). Chronic venlafaxine treatment fails to alter the levels of galanin system transcripts in normal rats. Neuropeptides 57: 65-70.

Pieribone VA, Xu ZQ, Zhang X, Grillner S, Bartfai T, Hokfelt T (1995). Galanin induces a hyperpolarization of norepinephrine-containing locus coeruleus neurons in the brainstem slice. Neuroscience 64: 861-874.

Porsolt RD, Le Pichon M, Jalfre M (1977). Depression: a new animal model sensitive to antidepressant treatments. Nature 266: 730-732.

Prut L, Belzung C (2003). The open field as a paradigm to measure the effects of drugs on anxiety-like behaviors: a review. Eur J Pharmacol 463: 3-33.

Razani H, Diaz-Cabiale Z, Fuxe K, Ogren SO (2000). Intraventricular galanin produces a time-dependent modulation of $5-\mathrm{HT} 1 \mathrm{~A}$ receptors in the dorsal raphe of the rat. Neuroreport 11: 3943-3948.

Razani H, Diaz-Cabiale Z, Misane I, Wang FH, Fuxe K, Ogren SO (2001). Prolonged effects of intraventricular galanin on a 5-hydroxytryptamine(1A) receptor mediated function in the rat. Neurosci Lett 299: 145-149.

Rovin ML, Boss-Williams KA, Alisch RS, Ritchie JC, Weinshenker D, West CH, et al. (2012). Influence of chronic administration of antidepressant drugs on mRNA for galanin, galanin receptors, and tyrosine hydroxylase in catecholaminergic and serotonergic cell-body regions in rat brain. Neuropeptides 46: 81-91.

Saar I, Runesson J, Jarv J, Kurrikoff K, Langel U (2013a). Novel galanin receptor subtype specific ligand in depression like behavior. Neurochem Res 38: 398-404.

Saar I, Lahe J, Langel K, Runesson J, Webling K, Jarv J, et al. (2013b). Novel systemically active galanin receptor 2 ligands in depression-like behavior. $J$ Neurochem 127: 114-123. 
Seutin V, Verbanck P, Massotte L, Dresse A (1989). Galanin decreases the activity of locus coeruleus neurons in vitro. Eur J Pharmacol 164: 373-376.

Sevcik J, Finta EP, Illes P (1993). Galanin receptors inhibit the spontaneous firing of locus coeruleus neurones and interact with mu-opioid receptors. Eur $J$ Pharmacol 230: 223-230.

Steru L, Chermat R, Thierry B, Simon P (1985). The tail suspension test: a new method for screening antidepressants in mice. Psychopharmacology (Berl) 85: 367-370.

Swanson CJ, Blackburn TP, Zhang X, Zheng K, Xu ZQ, Hokfelt T, et al. (2005). Anxiolytic- and antidepressant-like profiles of the galanin-3 receptor (Gal3) antagonists SNAP 37889 and SNAP 398299. Proc Natl Acad Sci U S A 102: 17489-17494.

Tatemoto K, Rokaeus A, Jornvall H, McDonald TJ, Mutt V (1983). Galanin - a novel biologically active peptide from porcine intestine. FEBS Lett 164: 124-128.

Wang P, Li H, Barde S, Zhang MD, Sun J, Wang T, et al. (2016). Depressionlike behavior in rat: Involvement of galanin receptor subtype 1 in the ventral periaqueductal gray. Proc Natl Acad Sci U S A 113: E4726-4735.

Wang YJ, Yang YT, Li H, Liu PZ, Wang CY, Xu ZQ (2014). Plasma galanin is a biomarker for severity of major depressive disorder. International journal of psychiatry in medicine 48: 109-119.

Weiss JM, Bonsall RW, Demetrikopoulos MK, Emery MS, West CH (1998). Galanin: a significant role in depression? Ann N Y Acad Sci 863: 364-382.

Wirz SA, Davis CN, Lu X, Zal T, Bartfai T (2005). Homodimerization and internalization of galanin type 1 receptor in living $\mathrm{CHO}$ cells. Neuropeptides 39: 535-546.

Wittchen HU, Jacobi F, Rehm J, Gustavsson A, Svensson M, Jonsson B, et al. (2011). The size and burden of mental disorders and other disorders of the brain in Europe 2010. Eur Neuropsychopharmacol 21: 655-679.

Wray NR, Pergadia ML, Blackwood DH, Penninx BW, Gordon SD, Nyholt DR, et al. (2012). Genome-wide association study of major depressive disorder: new results, meta-analysis, and lessons learned. Mol Psychiatry 17: 36-48. 
Xu ZQ, Hokfelt T (1997). Expression of galanin and nitric oxide synthase in subpopulations of serotonin neurons of the rat dorsal raphe nucleus. J Chem Neuroanat 13: 169-187.

Xu ZQ, Zhang X, Pieribone VA, Grillner S, Hokfelt T (1998). Galanin-5hydroxytryptamine interactions: electrophysiological, immunohistochemical and in situ hybridization studies on rat dorsal raphe neurons with a note on galanin R1 and R2 receptors. Neuroscience 87: 79-94.

Yamada M, Makino Y, Hashimoto T, Sugiyama A, Oka J, Inagaki M, et al. (2013). Induction of galanin after chronic sertraline treatment in mouse ventral dentate gyrus. Brain Res 1516: 76-82.

Yoshitake T, Reenila I, Ogren SO, Hokfelt T, Kehr J (2003). Galanin attenuates basal and antidepressant drug-induced increase of extracellular serotonin and noradrenaline levels in the rat hippocampus. Neurosci Lett 339: 239-242.

Figure 1. Expression levels of $G A L_{2}$ receptor $m R N A(A)$ and $G A L_{1}$ receptor mRNA $(C)$ in dorsal hippocampus. $(A, B)$ Expression levels of mRNA $G A L_{2}$ or $\mathrm{GAL}_{1}$ receptors (4 rats per group) measured on different days after administration of the Acell smart pool siRNA for $G A L_{2}$ receptor and $(C, D)$ expression levels of $m R N A G A L_{2}$ receptor or $G_{A} L_{1}$ receptor (4 rats per group) measured on different days after administration of the Acell smart pool siRNA for $\mathrm{GAL}_{1}$ receptor. The quantitative $\mathrm{PCR}$ results were normalized to the expression levels of GAPDH and expressed as arbitrary units. ${ }^{*} p<0.05$, ${ }^{* *} p<0.01$ vs Vehicle according to student's t-test. Modified from (Millon et al., 2015).

Figure 2. Close proximity between Galanin receptor 1 (GAL $L_{1}$ receptor) and Galanin receptor 2 (GAL2 receptor) and their effects in 5-HT synthesis and storage in RN33B cells. (A) Detection of close proximity between $G A L_{1}-G A L_{2}$ receptors in RN33B cells by in situ PLA. Scale bar, $10 \mu \mathrm{m}$. (B) Quantification of 5-HT immunoreactivity was analyzed after incubation with GAL and GAL(1-15) ${ }^{* * *} p<0.001$ according to one-way ANOVA followed by Newman Keuls Multiple 
Comparison Test. (C) Representative images of 5-HT stained RN33B cells under different conditions are presented. Scale bar, $10 \mu \mathrm{m}$. Modified from (Millon et al., 2015). (D) Representative schema illustrating the reduction of 5$H T$ in the dorsal raphe nuclei induced by the action of GAL(1-15) through the $\mathrm{GAL}_{1} / \mathrm{GAL}_{2}$ heteroreceptor complexes. Representative projections from $\mathrm{DR}$ to cortico-limbic areas are shown in red. 


\section{A}

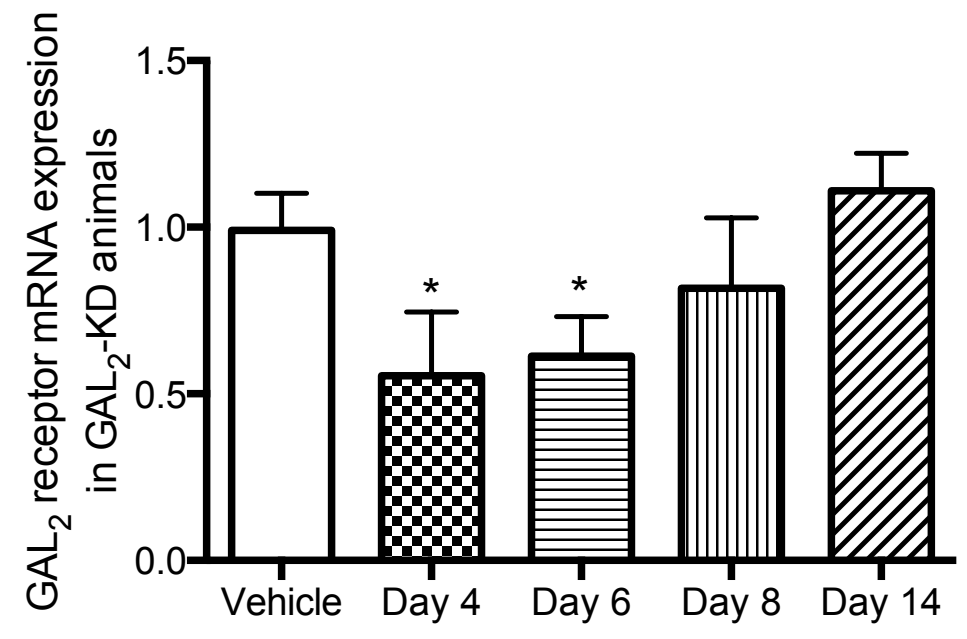

Figure 1

B
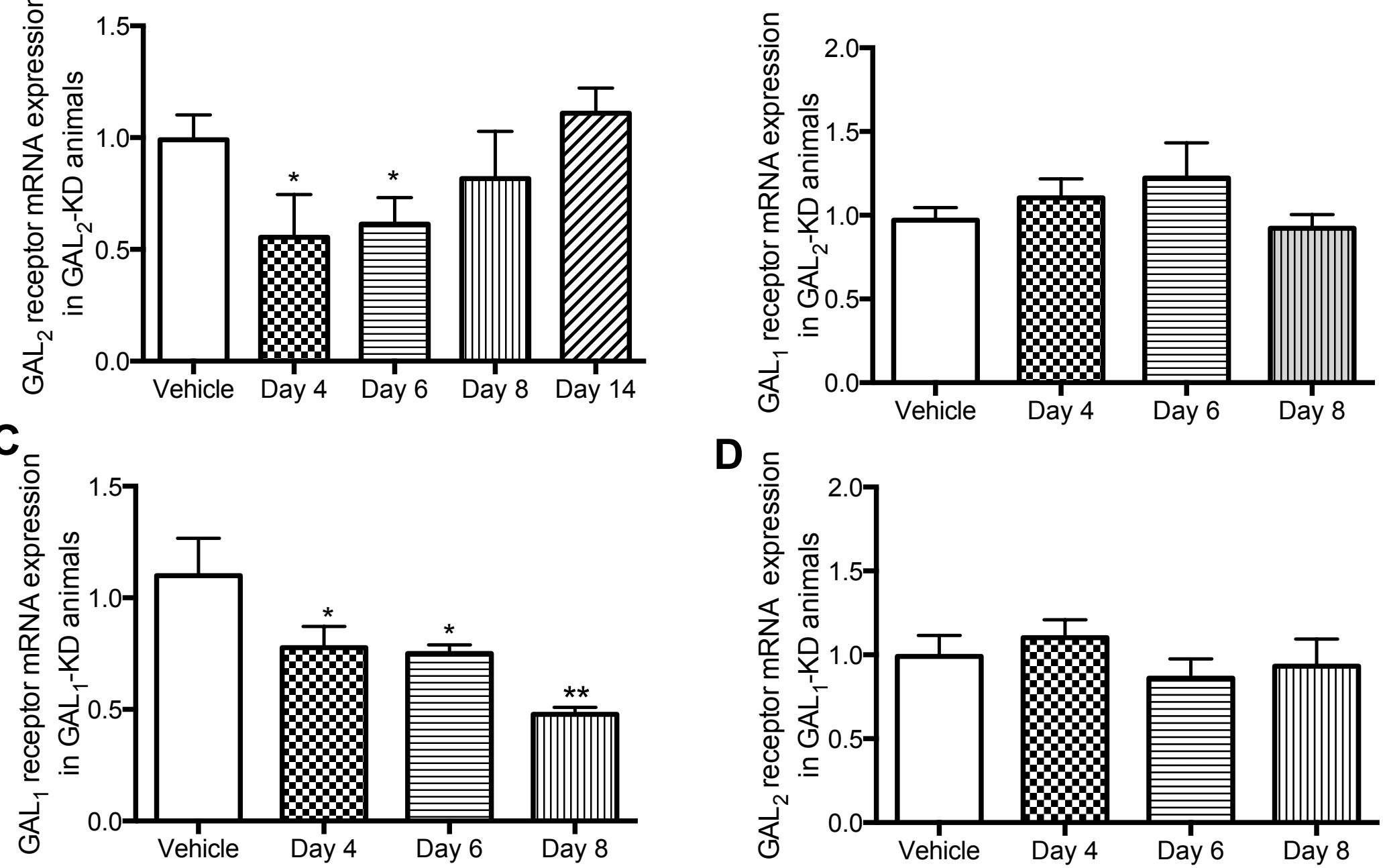

D

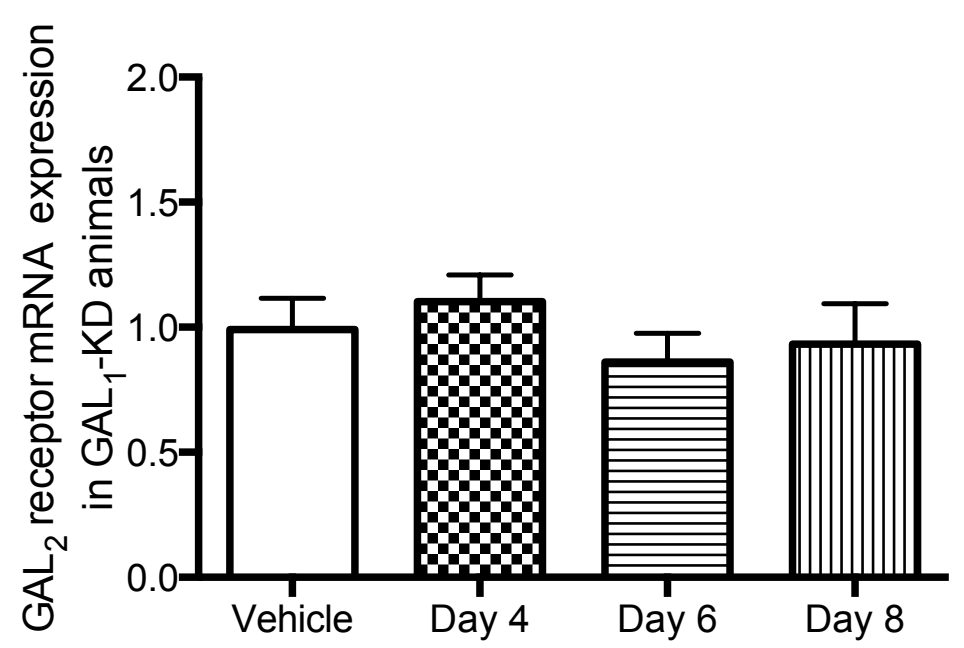




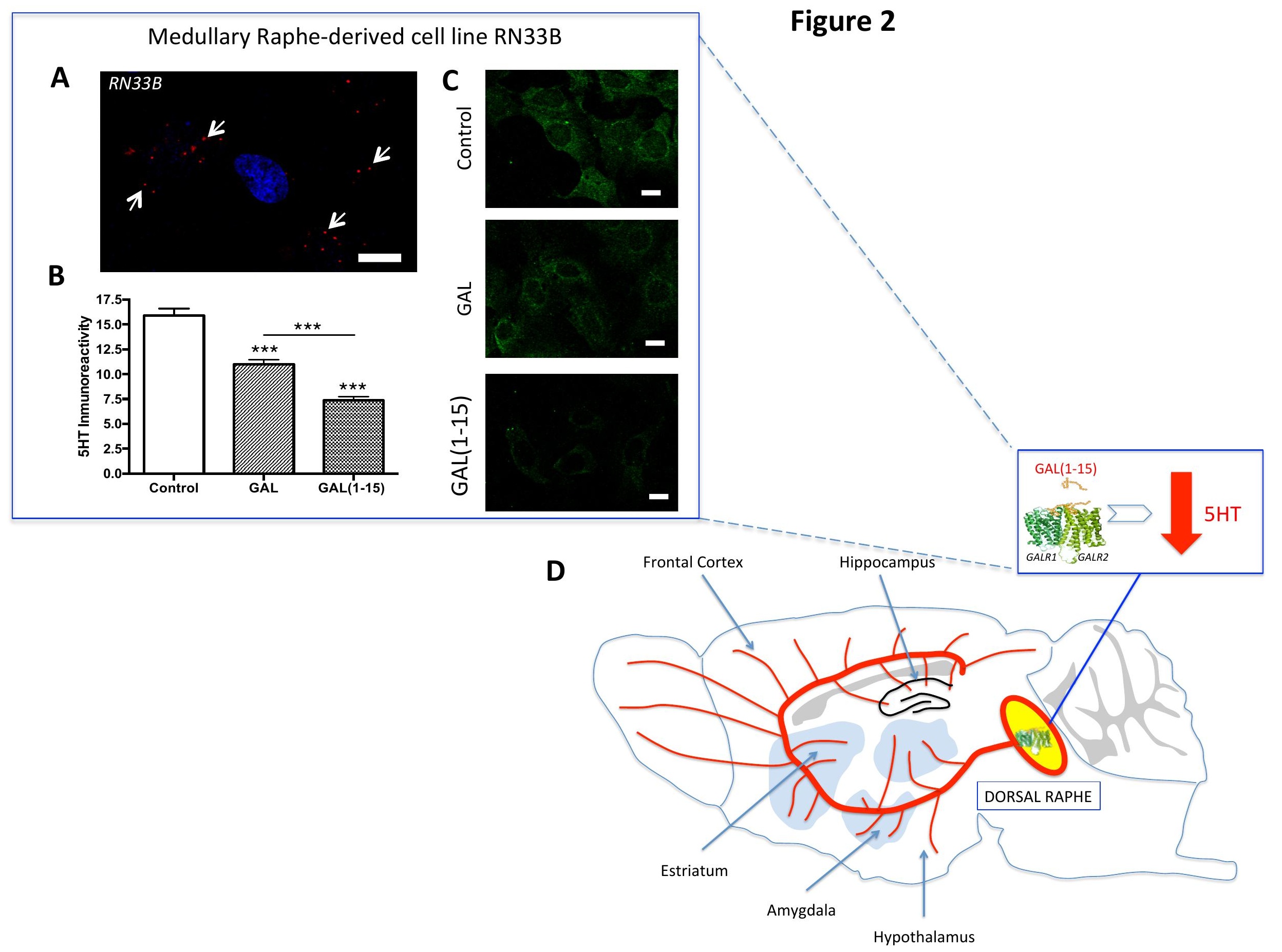




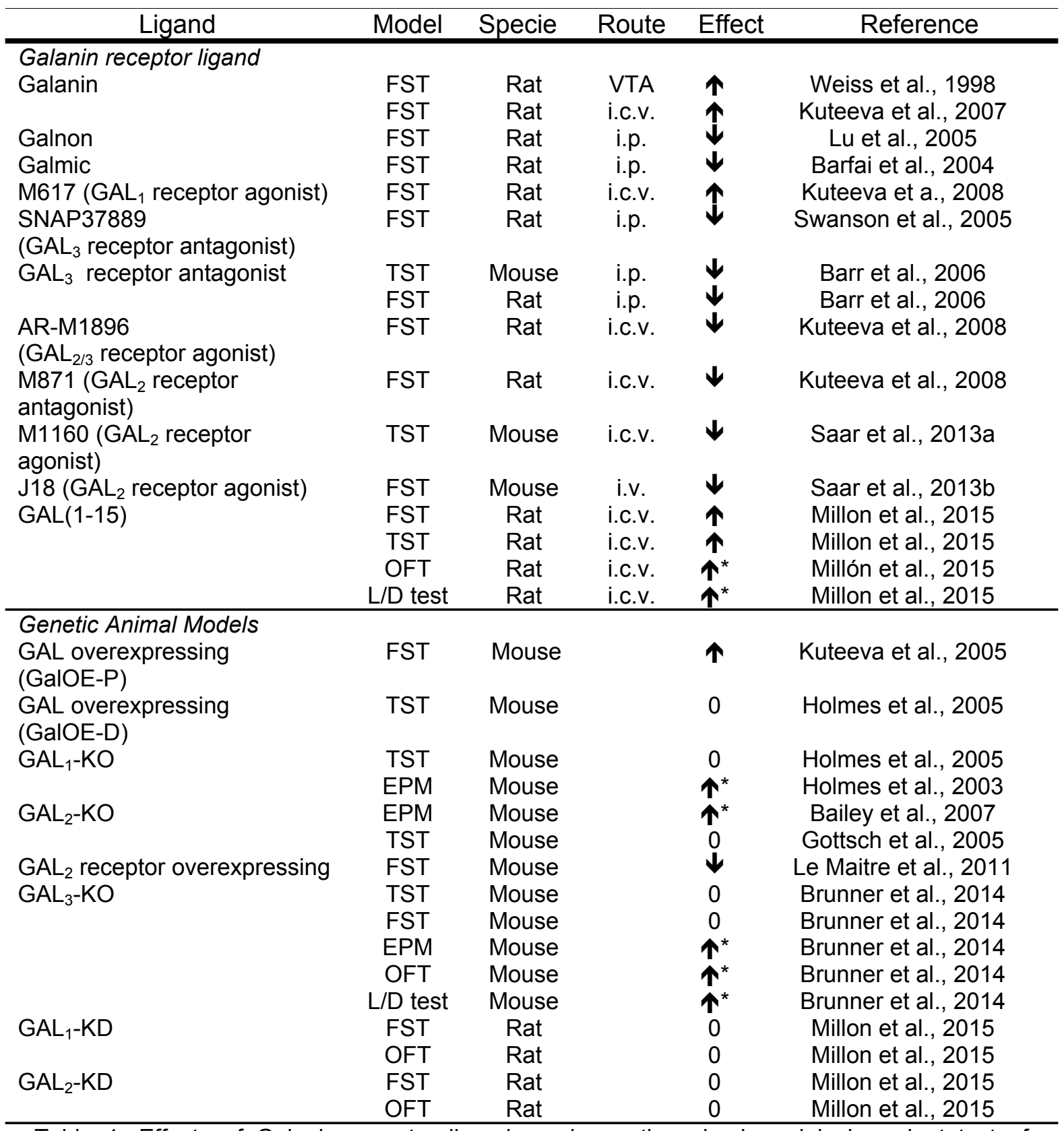

Table 1. Effects of Galanin receptor ligands and genetic animal models in rodent test of depression. FST: Forced Swimming Test; TST: Tail Suspension Test; OFT: Open Field Test; EPM: Elevated Plus Maze; L/D Test: Ligth-Dark test; VTA: Ventral Tegmentar Area; i.c.v.: intracerebroventricular; i.p.: intraperitoneal; i.v.: intravenous; KO: Knock Out; KD: Knock Down; $\uparrow$ : pro-depressive effect; 0 : no effect; $\downarrow$ : antidepressant effec; $\uparrow^{*}$ : anxiogenic effect. 


\title{
GALANIN (1-15) AND THE HETERODIMER GALR1/GALR2 IN DEPRESSION AND ANXIETY- LIKE BEHAVIOURS
}

Carmelo Millón ${ }^{1 *}$, Antonio Flores-Burgess ${ }^{1}$, Manuel Narváez ${ }^{1}$, Dasiel 0. Borroto-Escuela ${ }^{2}$, Belén Gago ${ }^{1}$, Luis Santín ${ }^{3}$, Estela Castilla-Ortega ${ }^{3}$, José Ángel Narváez ${ }^{1}$, Kjell Fuxe² \& Zaida Díaz-Cabiale ${ }^{1}$.

\begin{abstract}
Galanin is a 29 amino acid neuropeptide widely distributed in neurons within the central nervous system. Galanin exerts its biological activities through three different $G$ protein-receptors and participates in a number of functions, including mood regulation. Not only Galanin but also Galanin N-terminal fragments like Galanin(1-15) are active at the central level. In this work, we review the latest findings in studies on Galanin and Galanin(1-15) in depression-related behaviours. Our focus is on animal models for depression, and we pay some attention to research data obtained in human studies. Since Serotonin (5-HT), especially through 5-HT1A, and Galanin receptors interact at both pre-and postsynaptic level, the development of drugs targeting potential $G A L_{1}-G A L_{2}-5-$ HT1A heteroreceptor complexes linked to the raphe-hippocampal 5-HT neurons may represent new treatment strategies in depression.
\end{abstract}

Key words: depression, galanin 


\section{Highlights}

- $\mathrm{GAL}(1-15)$ produces depression- and anxiety- like effects in behavioural test.

- In these tests, GAL(1-15) induces stronger effects than GAL.

- GALR1/GALR2 heteroreceptor complexes are involved in GAL(1-15)-mediated action. 